\title{
Design and synthesis of nanoporous perylene bis-imide linked metalloporphyrin frameworks and their catalytic activity
}

\author{
MANOJ KUMAR SINGH and DEBKUMAR BANDYOPADHYAY* \\ Department of Chemistry, Indian Institute of Technology Delhi, HauzKhas, New Delhi 110 016, India \\ e-mail:dkbp@chemistry.iitd.ac.in
}

MS received 25 August 2015; revised 29 September 2015; accepted 19 October 2015

\begin{abstract}
Two nanoporous perylene bis-imide linked metalloporphyrin framework catalysts have been synthesized via condensation of 5,10,15,20-tetrakis-(4'-aminophenyl) iron(III) porphyrin chloride or 5,10, 15,20-tetrakis-(4'-aminophenyl) manganese(III) porphyrin chloride with perylene-3,4,9,10-tetracarboxylic dianhydride. Both the materials were crystalline in nature and were characterized by electron microscopy techniques, solid-state ${ }^{1} \mathrm{H}-{ }^{13} \mathrm{C} \mathrm{CP} / \mathrm{MS}$ NMR, powder X-ray diffraction (PXRD), and magnetic susceptibility measurements. The nitrogen gas physisorption study has indicated that both materials are porous in nature and have BET surface area with $653 \mathrm{~m}^{2} / \mathrm{g}$ and $974 \mathrm{~m}^{2} / \mathrm{g}$ with uniform pore size of $2.8 \mathrm{~nm}$. These materials were found to act as very good heterogeneous catalysts for selective oxidation of alkanes and alkenes with tert-butyl hydroperoxide and were not degraded even after multiple uses up to 10 cycles.
\end{abstract}

Keywords. Covalent-organic frameworks (COFs); metalloporphyrins; heterogeneous catalysis; oxidation.

\section{Introduction}

Iron(III) and manganese(III) porphyrin catalysed oxidation of alkanes and alkenes remained an interesting area of research for several decades till date. ${ }^{1-5}$ In the early stages, it has been noted that tetrakis-phenyl porphyrin iron(III) and manganese(III) complexes were good to mimic the reactions of Cytochrome P450 enzymes but in both cases the catalysts were damaged by the now known $\mu$-oxo-bridged product formation. ${ }^{6}$ In order to resolve the issue, electronegatively substituted porphyrins were prepared and their iron(III) and manganese(III) complexes were found to be relatively more efficient but the problem of the catalyst degradation was not really resolved. ${ }^{7}$ In the course of our own studies also, the degradation of such electronegatively substituted iron(III) porphyrin catalysts were noted in similar studies. ${ }^{8-10}$ There was good success on catalyst stabilization in attaching the functionalized porphyrins over silica or polymeric catalysts but the surface area of the active catalyst was difficult to measure accurately. ${ }^{11,12}$ In recent studies, the focus has been to make inorganic coordination polymers (CP) or metal-organic frameworks (MOFs) with these metalloporphyrins. ${ }^{13,14}$ In CP materials the activity of the catalysts were improved but the solvolytic decay of the materials to the monomers caused finally the destruction of the catalyst.

\footnotetext{
*For correspondence
}

Thus, at present the focus has been on covalently linked metalloporphyrin frameworks materials. ${ }^{15-17}$ These covalently linked metalloporphyrin materials are amorphous in nature, their catalytic ability and stability have been improved a lot. In these studies, it has been observed that when these covalent organic frameworks (COFs) materials are prepared through reversible organic reaction pathways the materials become crystalline in nature. It is believed that reversibility in covalent bond formation during synthesis is required for making crystalline COFs. This probably suggests why the materials prepared by the irreversible organic reactions (Suzuki coupling) were always amorphous in nature. ${ }^{18,19}$ Thus, by taking help of such reversible organic reactions, such as, boronic acid trimerization, Schiff base reaction, hydrazine and squaraine linkage and nitrile trimerization several crystalline COFs are reported. ${ }^{20-24}$ The COF materials are in general porous and are found to be very useful in gas storage/separation, ${ }^{25-27} \mathrm{CO}_{2}$ capture, ${ }^{28-30}$ sensors, ${ }^{31,32}$ and catalysis. ${ }^{33-35}$ The amorphous materials of large pore sizes are indeed found to be more efficient catalysts. ${ }^{36,37}$ In our endeavour also we have noted that the materials prepared by irreversible route (Suzuki coupling) became amorphous, though their catalytic oxidizing ability was good. ${ }^{38}$ Herein we report our successful result of making two crystalline materials where an imide bond is formed between the metalloporphyrin moiety and perylene bis anhydride and the material is nanoporous with 
larger pore size. The solid state properties and the catalytic oxidation of these two materials with $t$-BuOOH are also discussed.

\section{Experimental}

\subsection{Catalyst Preparation}

Details of synthesis and characterization of free base porphyrin and metallated porphyrin are given in the Supporting Information. The two nanoporous perylene bis-imide linked metalloporphyrin frameworks were synthesized by the following methods:

2.1a Synthesis of perylenebis-imide linked iron(III) porphyrin chloride: Perylene bis-imide linked iron(III) porphyrin chloride (1) was synthesized by refluxing $5,10,15,20$-tetrakis-(4'-aminophenyl) iron(III) porphyrin chloride (120 mg, $0.155 \mathrm{mmol}$ ) and perylene-3,4,9, 10-tetracarboxylic dianhydride (122 mg, $0.320 \mathrm{mmol})$ in $\mathrm{m}$-cresol $(25 \mathrm{~mL})$ under argon. Isoquinolene $(2 \mathrm{~mL})$ was then added to the refluxing mixture after $15 \mathrm{~min}$. The refluxing was continued for $24 \mathrm{~h}$, and then the reaction mixture was brought to room temperature and was poured into methanol $(50 \mathrm{~mL})$. The solid residue was filtered by G-4 and was washed with THF (5 $\mathrm{mL})$, methanol $(15 \mathrm{~mL})$ and acetone $(10 \mathrm{~mL})$. Finally the solid was washed by soxlet extractor using THF, methanol and acetone (100 mL each) respectively for $24 \mathrm{~h}$, and then dried in vacuum to give polymeric material $(\sim 130 \mathrm{mg})$ as a reddish crystalline solid (in $54 \%$ isolated yield). Elemental analysis (\%) Calcd. For $\left\{\mathrm{C}_{92} \mathrm{H}_{40} \mathrm{ClFeN}_{10} \mathrm{O}_{8}\right\}_{\mathrm{n}}$ (Theoretical formula for an infinite $2 \mathrm{D}$ polymer) $\mathrm{C} 73.44, \mathrm{H} \mathrm{2.68}, \mathrm{N} 9.31$, Found by combustion: C 70.47, H 2.81, N 9.06. Fe Content by ICP-AAS: 3.53 wt \%; Found by EDX analysis (wt \%): Fe 3.66. FT IR $\left(v ; \mathrm{cm}^{-1}\right): 3118,1769,1698,1588$, $1504,1401,1350,1299,1237,1124,1020(\delta \mathrm{Fe}-\mathrm{N})$, 858, 803and 736. UV-Vis $(\lambda, \mathrm{nm}): 375,451,533$ and 578.

2.1b Synthesis of perylenebis-imide linked manganese(III)porphyrin chloride: Perylene bis-imide linked manganese(III) porphyrin chloride (2) was similarly synthesized by refluxing 5,10,15,20-tetrakis-(4'aminophenyl) manganese(III) porphyrin chloride (120 $\mathrm{mg}, 0.155 \mathrm{mmol}$ ) and perylene-3,4,9,10-tetracarboxylic dianhydride (122 $\mathrm{mg}, 0.320 \mathrm{mmol})$ in $\mathrm{m}$-cresol (25 $\mathrm{mL})$ under argon. Isoquinolene $(2 \mathrm{~mL})$ was then added to the refluxing mixture after $15 \mathrm{~min}$. The refluxing was continued for $24 \mathrm{~h}$, and then the reaction mixture was brought to room temperature and was poured into methanol $(50 \mathrm{~mL})$. The solid residue was filtered by G-4 and was washed with THF ( $5 \mathrm{~mL})$, methanol (15 $\mathrm{mL})$ and acetone $(10 \mathrm{~mL})$. Finally the solid was washed by soxlet extractor using THF, methanol and acetone (100 $\mathrm{mL}$ each), respectively for $24 \mathrm{~h}$, and then dried in vacuum to give polymeric material $(\sim 150 \mathrm{mg})$ as a purple crystalline solid (in $62 \%$ isolated yield). Elemental analysis (\%) Calcd. For $\left\{C_{92} \mathrm{H}_{40} \mathrm{ClMnN}_{10} \mathrm{O}_{8}\right\}_{\mathrm{n}}$ (Theoretical formula for an infinite $2 \mathrm{D}$ polymer) $\mathrm{C} 73.44, \mathrm{H}$ 2.68, N 9.31, Found by combustion: C 71.43, H 2.82, N 9.24. Mn Content by ICP-AAS: $4.07 \mathrm{wt} \%$; Found by EDX analysis (wt \%): Mn 3.93. FT IR $\left(v, \mathrm{~cm}^{-1}\right): 3119$, 1770, 1699, 1660, 1589, 1502, 1404, 1351, 1300, 1234, 1124, $1020(\delta \mathrm{Mn}-\mathrm{N}), 860,803$ and 732. UV-Vis $(\lambda$, $\mathrm{nm}): 376,477,535$ and 580.

\subsection{Catalyst characterization}

The ${ }^{1} \mathrm{H}$ NMR spectra were recorded on a Bruker spectrospin DPX-300 NMR spectrometer at 300.13 and $75.47 \mathrm{MHz}$, respectively, using $\mathrm{CDCl}_{3}$ as a solvent at room temperature. Mass spectra (HRMS) were recorded in the electro-spray ionization (ESI) mode $\left(10 \mathrm{eV}, 180^{\circ} \mathrm{C}\right.$ source temperature and sodium formate as calibrant) on a Bruker micrOTOF-QII, taking the samples in acetonitrile/methanol. Solid-state ${ }^{1} \mathrm{H}-{ }^{13} \mathrm{C}$ CP/MAS NMR measurements were performed on a Bruker model $500 \mathrm{MHz}$ NMR spectrometer at a MAS rate of $15 \mathrm{kHz}$ and a CP contact time of $5 \mathrm{~ms}$. Magnetic susceptibility measurements were carried out with Quantum Design model MPMS XL7 SQUID magnetometer. UV-Vis absorption spectra were measured in $\mathrm{CH}_{2} \mathrm{Cl}_{2}$ in a quartz cell of $1-\mathrm{cm}$ path length on an Agilent Technologies 8453 model spectrometer and the diffuse reflectance spectra (Kubleka-Munk spectrum) were recorded on a Perkin Elmer UV-Vis Lambda Bio 20 model spectrometer. Infrared spectra were recorded on an Agilent Technologies Cary 660 model Fourier transform infrared spectrophotometer. Elemental analysis of $\mathrm{C}, \mathrm{H}$, and $\mathrm{N}$ were carried out on a Perkin Elmer instrument series II CHNS/O Analyser 2400 model. Fe and Mn contents were measured by ICP-AAS method on a Perkin Elmer instruments Analyst 100 model plasma spectrometer. Scanning electron microscopy and energy dispersive X-ray spectroscopy were performed on a ZEISS EVO Series model EVO50 microscope operating at an accelerating voltage of 5.0 $\mathrm{kV}$. Powder X-ray data were collected on a Bruker D8 Advance diffractometer using Ni-filtered $\mathrm{CuK} \alpha$ radiation. Data were collected with a step size of $0.02^{\circ}$ and a count time of $2 \mathrm{~s}$ per step over the range $5^{\circ}<2 \theta<70^{\circ}$. Nitrogen sorption isotherms were measured with Quantachrome NovaWin-Data Acquisition 
analyzer and reduction for NOVA instruments, Quantachrome Instruments version 10.01 at $77 \mathrm{~K}$. Before measurement, the samples were degassed in vacuum at $200^{\circ} \mathrm{C}$ for more than $12 \mathrm{~h}$. The BrunauerEmmett-Teller (BET) method was utilized to calculate the specific surface areas and the nonlocal density function theory was applied for the estimation of pore size, pore volume and pore distribution.

\subsection{Catalytic Experiments}

The catalytic oxidations of various olefins were carried out in 4-mL pyrex glass reactors equipped with mechanical stirrer. In a typical experiment, 1 or $2(5$ $\mathrm{mg})$, dichloromethane $(2 \mathrm{~mL})$, alkanes/alkenes (400 $\mathrm{mM})$ and TBHP $(10 \mathrm{mM})$ were charged in the reactor and the resulting mixture was stirred under an atmosphere of argon at $298 \mathrm{~K}$. The solution was periodically analysed by GC-MS (Perkin Elmer Auto System XL gas chromatography equipped with a Flame Ionization Detector (FID). All the products were identified by the comparison of GC retention times of the standard samples. Selectivity and conversion were calculated with respect to oxidant. For the recycling experiments, after the first reaction was over (6-8 $\mathrm{h}$ ) another batch of TBHP $(\sim 3 \mu \mathrm{L})$ was added to the same pot and the reaction was continued for another $8 \mathrm{~h}$ and then monitored by GC. The process was repeated similarly for 10 cycles and the products were analysed each time as stated for the first cycle.

\section{Results and Discussion}

Considering the known structural features of the porphyrin and perylene, the most probable structure of the proposed materials is shown in scheme 1 . These materials were however characterized by various spectroscopic techniques such as elemental analysis, electron microscopy and Powder X-ray diffraction (PXRD) measurements.

Infrared (IR) spectroscopy provided evidence for the presence of imide linkage in $\mathbf{1}$, showing the characteristic vibration bands at $1695 \mathrm{~cm}^{-1}$ and $1353 \mathrm{~cm}^{-1}$ for imide carbonyl and $\mathrm{C}-\mathrm{N}$ units, respectively (figure $\mathrm{S} 1$, table S2 in Supplementary Information). After condensation reaction, compound $\mathbf{1}$ did not exhibit the signal of the anhydride carbonyl group. This observation indicated that the anhydride units have been transformed to imide. The Fe-N stretching frequency of metalloporphyrin was observed at $1020 \mathrm{~cm}^{-1}$. Elemental analysis showed the content of $\mathrm{C}, \mathrm{H}$, and $\mathrm{N}$ to be 70.47, 2.81 and $9.06 \%$, respectively (theoretical formula for an infinite $2 D$ polymer $\left\{\mathrm{C}_{92} \mathrm{H}_{40} \mathrm{ClFeN}_{10} \mathrm{O}_{8}\right\}_{\mathrm{n}} \mathrm{C} 73.44 \%, \mathrm{H} 2.68 \%$, $\mathrm{N} 9.31 \%)$. The amount of iron $(3.53 \mathrm{wt} \%)$ and manganese (4.07 wt \%) in $\mathbf{1}$ and $\mathbf{2}$ were estimated by ICPAAS (Inductively coupled plasma atomic absorption spectroscopy). Similar type of IR pattern was observed for 2 (figure S1, table S3), showing that these two materials are isomorphous in nature.

Perylene is a well-known electron acceptor moiety which in combination with the metalloporphyrin in COFs may affect the $\pi-\pi^{*}$ transitions of both molecules. Therefore, their $\pi$ electronic properties are interesting to be elucidated. We conducted solidstate electronic absorption spectroscopy to evaluate the absorption bands of $\mathbf{1}$ and $\mathbf{2}$ (figures 1a and b).

Compound 1 displayed absorption band at $451 \mathrm{~nm}$ attributed to the soret bands of iron(III) porphyrin unit. The band at $533 \mathrm{~nm}$ appeared due to the imide bond formation with the perylene moiety. There is a $24 \mathrm{~nm}$ red shift of the soret band of $\mathbf{1}$ with respect to the corresponding $\left(\mathrm{NH}_{2}\right)_{4} \mathrm{TPPFeCl}$ monomer $(427 \mathrm{~nm})$. The compound 2 also exhibited the characteristic imidic

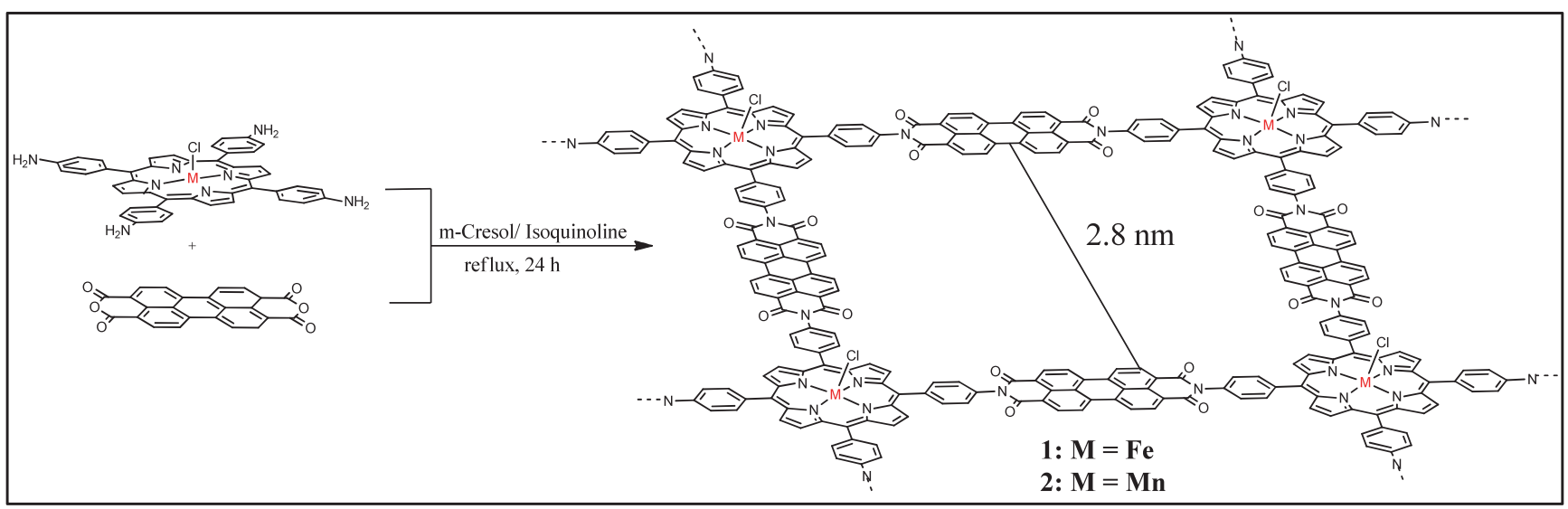

Scheme 1. The general strategy for the synthesis of imide-linked metalloporphyrin COFs 

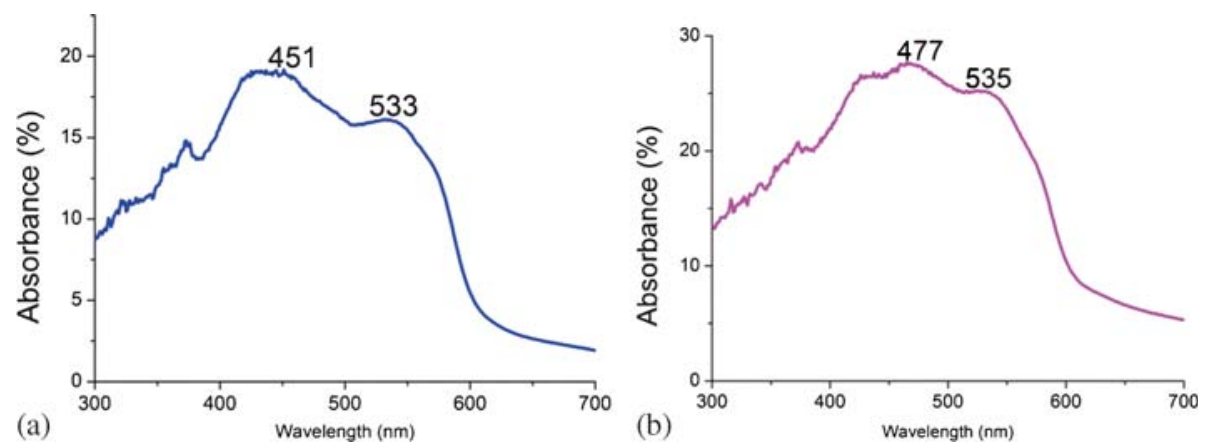

Figure 1. Absorption spectra computed from the diffuse reflectance spectra (a) for compound $\mathbf{1}$ and (b) for compound $\mathbf{2}$.
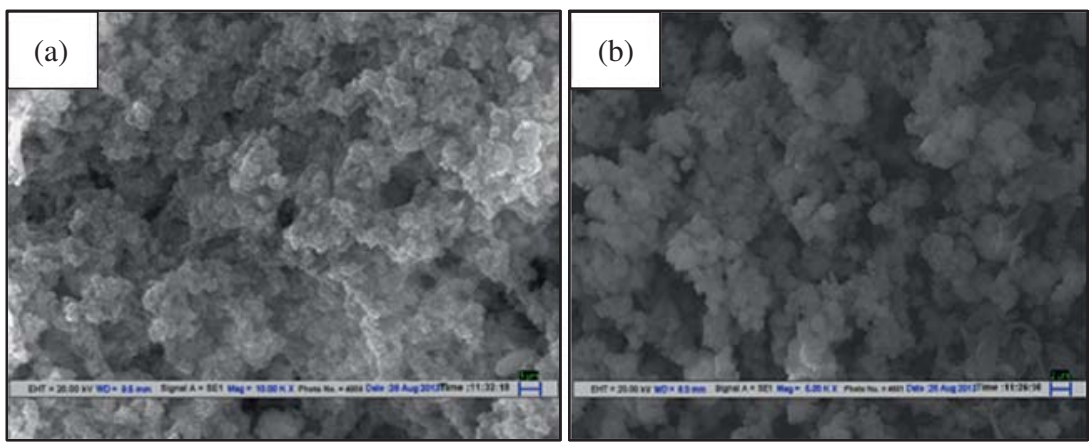

Figure 2. SEM images at magnification (a) 10000X (scale $1 \mu \mathrm{m}$ ) and (b) 6000X (scale $2 \mu \mathrm{m}$ ).

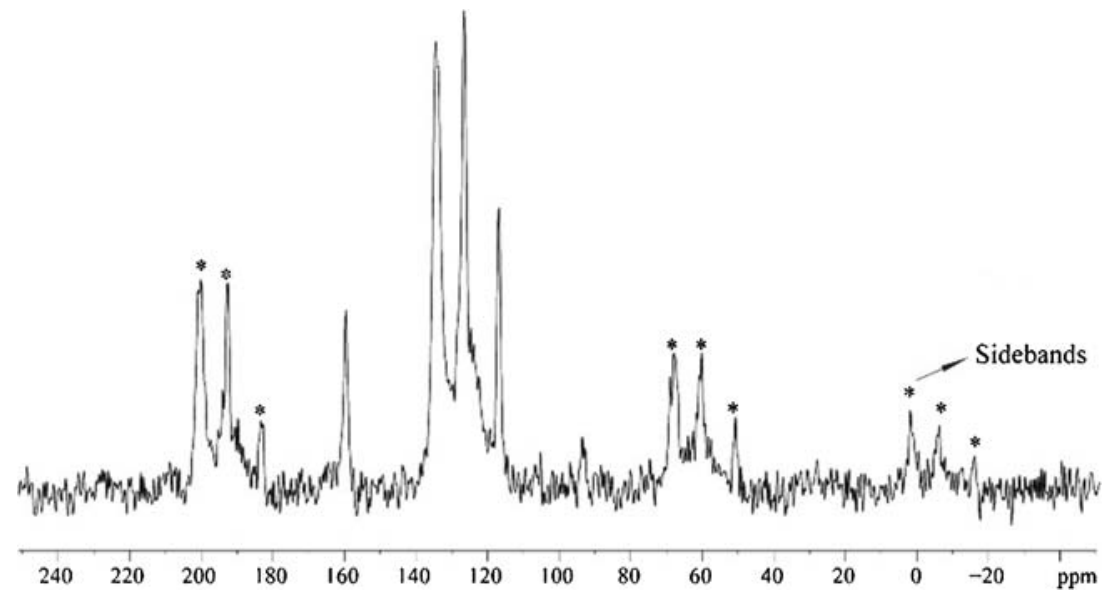

Figure 3. Solid-state ${ }^{1} \mathrm{H}-{ }^{13} \mathrm{C}$ CP/MS NMR spectrum of perylene bis-imide linked iron(III) porphyrin COF, recorded at a MAS rate of $15 \mathrm{kHz}$ and a $\mathrm{CP}$ contact time of $5 \mathrm{~ms}$. Signals marked with * are side bands.

unit at $535 \mathrm{~nm}$. These results indicated the presence of extended $\pi$ conjugation over the $2 \mathrm{D}$ sheet of the COFs.

Scanning electron microscopy (SEM, figure 2a and b) revealed that $\mathbf{1}$ has rough surface with length of several tens of micrometres and width of $\sim 100 \mathrm{~nm}$. The presence of iron and manganese in $\mathbf{1}$ and $\mathbf{2}$ were confirmed by elemental analysis EDX (Energy dispersive $\mathrm{X}$-ray, figures S2 and S3 in SI).
The compounds $\mathbf{1}$ and $\mathbf{2}$ are stable and insoluble in common organic solvents. Magnetic susceptibility measurements at room temperature indicated that both the materials are at high spin state due to the $\mathrm{d}^{5}$ and $\mathrm{d}^{4}$ electronic configuration of $\mathrm{Fe}$ (III) and $\mathrm{Mn}$ (III) (figures $\mathrm{S} 4$ and S5 in SI), respectively. Owing to the high-spin paramagnetic effect, the solid-state ${ }^{1} \mathrm{H}-{ }^{13} \mathrm{C}$ CP/MS NMR spectrum of COFs gave only a weak and broad 

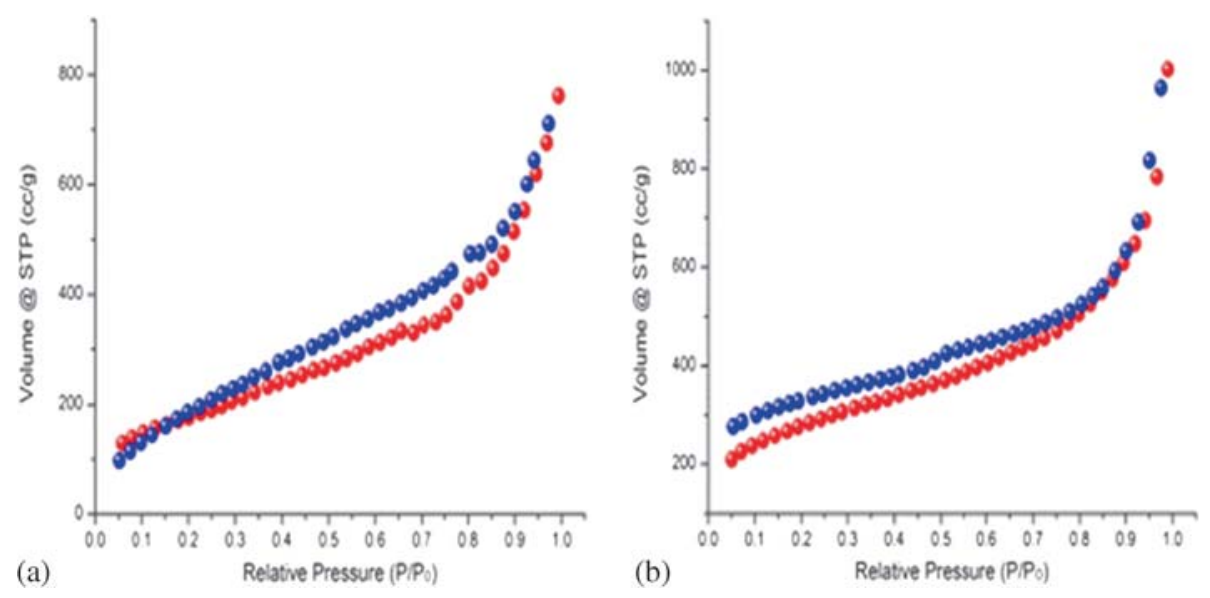

Figure 4. Nitrogen sorption isotherm (absorption (Red), desorption (Blue)) of (a) Perylene bis-imide linked iron(III) porphyrin and (b) Perylene bis-imide linked manganese(III) porphyrin, measured at $77 \mathrm{~K}$.

signal. The compound $\mathbf{1}$ displayed two broad peaks at 136 and $128 \mathrm{ppm}$ assignable to the perylene linkages and signals at 118 and $159 \mathrm{ppm}$ owing to the porphyrin macrocycles (figure 3).

In order to understand the nature of the materials (crystalline or amorphous), XRD measurements were conducted (figures S6 and S7 in SI). The compound 1 and 2 exhibited distinct diffraction peaks at 8.56, 12.28, 24.76 and 28.18 degrees. Interestingly, the peak positions of both the materials were at the same position,

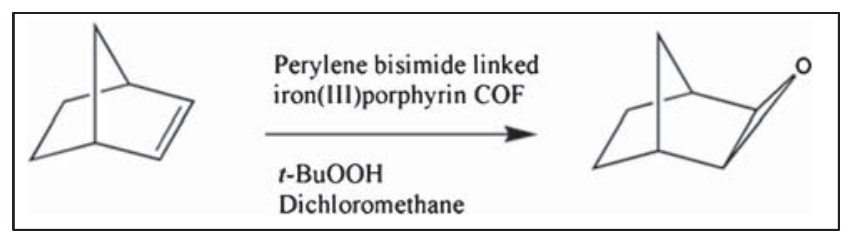

Scheme 2. Reaction scheme for oxidation of norbornene to exo-2,3-epoxy norbornane. which indicated that the crystalline skeleton of these two materials are similar. It also probably indicates that the facets of both the materials are similarly oriented and thus these materials may be classified under 2D COFs materials.

In order to understand the $1 \mathrm{D}$ channel accessibility and porosity of the COF materials, nitrogen sorption isotherm measurements were conducted for these two materials. Both displayed typical type-IV sorption isotherm curve (figure 4) which is the characteristic of mesoporous materials. The calculated BET surface areas were 653 and $974 \mathrm{~m}^{2} / \mathrm{g}$; the Langmuir surface areas were 1042 and $1489 \mathrm{~m}^{2} / \mathrm{g}$ for $\mathbf{1}$ and $\mathbf{2}$, respectively. The total pore volumes were estimated to be 1.1 and $1.2 \mathrm{~cm}^{3} \mathrm{~g}^{-1}$ for $\mathbf{1}$ and $\mathbf{2}$, respectively. The pore size distributions were evaluated by using the nonlocal density functional theory (NL-DFT) method (figure S8). The polymer has one main peak centred at 2.8 $3.2 \mathrm{~nm}$, which is close to the theoretical value $(2.8 \mathrm{~nm})$.

Table 1. Oxidation of norboronene with $t$-BuOOH in $\mathrm{CH}_{2} \mathrm{Cl}_{2}$ at $25 \pm 2{ }^{\circ} \mathrm{C}$.

\begin{tabular}{|c|c|c|c|c|c|c|}
\hline \multirow[b]{2}{*}{ Sl. No. } & \multirow[b]{2}{*}{ Time (h) } & \multirow[b]{2}{*}{ Oxidant } & \multicolumn{3}{|c|}{ Exo-2,3-epoxynorbornane yield $\%$ b } & \multirow[b]{2}{*}{ Catalyst 2} \\
\hline & & & $\left(\mathrm{NH}_{2}\right)_{4} \mathrm{TPPFeCl}$ & $\left(\mathrm{NH}_{2}\right)_{4} \mathrm{TPPMnCl}$ & Catalyst 1 & \\
\hline 1 & 0.25 & 2 & 8 & 7 & 15 & 17 \\
\hline 2 & 1 & 4 & 15 & 16 & 30 & 35 \\
\hline 3 & 2 & 6 & 18 & 20 & 34 & 49 \\
\hline 4 & 3 & 6 & 20 & 23 & 42 & 61 \\
\hline 5 & 4 & 6 & 22 & 27 & 54 & 76 \\
\hline 6 & 5 & 6 & 25 & 30 & 65 & 88 \\
\hline 7 & 6 & 6 & 28 & 33 & 72 & $>99$ \\
\hline 8 & 7 & 6 & 30 & 35 & 84 & $>99$ \\
\hline 9 & 8 & 6 & 31 & 35 & $>99$ & $>99$ \\
\hline
\end{tabular}

[a] norbornene $(400 \mathrm{mmol})$, TBHP $(10 \mathrm{mmol})$, catalyst $(3.16 \mu \mathrm{mol})$, dichloromethane $(2.0 \mathrm{~mL})$ and dodecane $(5 \mathrm{~mL}) \mathrm{sealed}$ as internal standard in a Teflon-lined screw capped vial and stirred at room temperature for $8 \mathrm{~h}$. [b] Conversion [\%] was determined by GC. The yields are w.r.t. oxidant. 


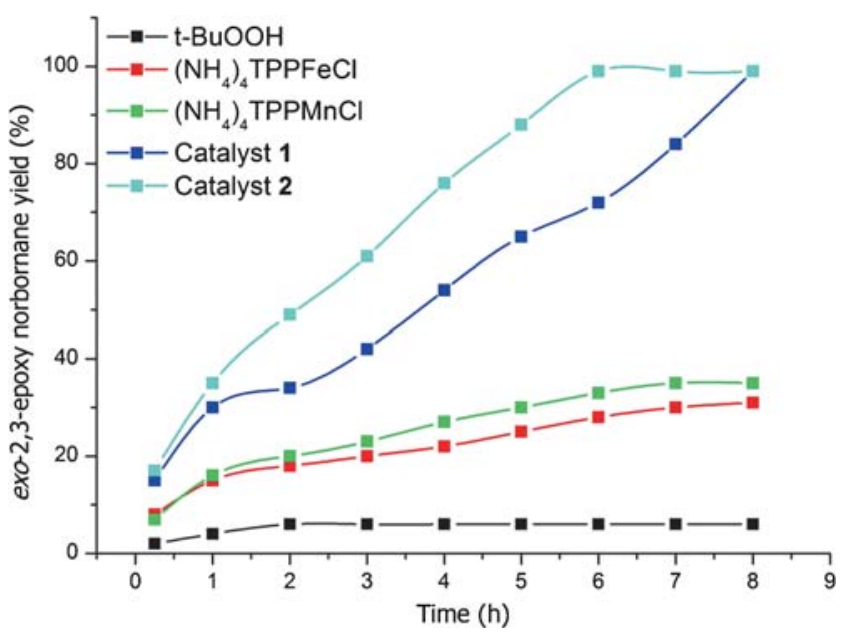

Figure 5. Plot of yield \% of exo-2,3-epoxy nornoronane vs time (h) for Catalyst $\mathbf{1}$, Catalyst $2,\left(\mathrm{NH}_{4}\right)_{2} \mathrm{TPPFe}(\mathrm{III}) \mathrm{Cl}$, $\left(\mathrm{NH}_{4}\right)_{2} \mathrm{TPPMn}(\mathrm{III}) \mathrm{Cl}$ and only oxidant $t$-BuOOH in dichloromethane.
These results indicated that these COFs materials may be good hosts for suitable gaseous guest molecules or other substrates of appropriate size.

Now on the basis of these results, we believe that both these materials to be very good catalysts to mimic the oxidation reaction of cytochrome P450. As a test case we have chosen norbornene as the substrate and $t$ - $\mathrm{BuOOH}$ as the oxidant and the results are given below. In a typical reaction norbornene was found to be selectively oxidized to exo-norbornane oxide (scheme 2).

Norbornene was oxidized to exo-2,3-epoxynorbornane in $6 \%$ yield in $8 \mathrm{~h}$ by $t$ - $\mathrm{BuOOH}$ alone. The yield was improved to $31 \%$ when monomeric catalyst $\left(\mathrm{NH}_{2}\right)_{4}$ $\mathrm{TPPFeCl}$ was present in the medium. However, the yield of epoxide was substantially increased to $>99 \%$ under identical reaction conditions when catalyst $\mathbf{1}$ or $\mathbf{2}$ was used (table 1).

The plot of the product yield vs. time for noncatalytic (only oxidant), with monomeric catalyst, with catalyst $\mathbf{1}$ and catalyst $\mathbf{2}$ are given in figure 5. The plot

Table 2. Perylene bis-imide linked Fe(III) porphyrin COF catalysed epoxidation/oxidation of alkenes/alkanes. ${ }^{\text {a }}$

\begin{tabular}{lcccc}
\hline Sl. No. & Substrate & Product & Conversion $(\%)$ & Selectivity $^{\mathrm{c}}(\%)$ \\
\hline 1 & Norbornene & Norbornane epoxide & 99 & 99 \\
2 & Cyclooctene & Octane epoxide & 99 & 99 \\
3 & Cyclohexene & Cyclohexen-1-one & 99 & 70 \\
4 & Styrene & Styrene epoxide & $99^{[\mathrm{d}]}$ & 65 \\
5 & Cyclohexane & Cyclohexane-1-one & $28^{[\mathrm{e}]}$ & 60 \\
6 & Cyclooctane & Cyclooctane-1-one & $58^{[\mathrm{f}]}$ & 75 \\
7 & 1-Hexene & Hexene epoxide & $92^{[\mathrm{g}]}$ & 35 \\
\hline
\end{tabular}

[a] alkenes/alkane (400 mmol), TBHP (10 mmol), catalyst $(3.16 \mu \mathrm{mol})$, dichloromethane $(2.0 \mathrm{~mL})$ and dodecane $(5 \mathrm{~mL})$ sealed as internal standard in a Teflon-lined screw capped vial and stirred at room temperature for $8 \mathrm{~h}$. [b] Conversion [\%] and [c] selectivity [\%] were determined by GC. The yields are w.r.t. oxidants. [d] The by-products were benzaldehyde and benzenacetaldehyde. [e] Cyclohexane-1-one (17\%) and cyclohexane-1-ol (11\%). [f] Cyclooctane-1-one (44\%) and cyclooctane1-ol (14\%). [g] Hexane epoxide (32\%), 1-hexene-3-one (27\%), 2-hexenal (20\%) and by-products were 1-hexene-3-ol (8\%) and 2-hexene-1-ol (5\%). The yields are w.r.t. oxidant.

Table 3. Perylene bis-imide linked Mn(III) porphyrin COF catalysed epoxidation/oxidation of alkenes/alkanes. ${ }^{a}$

\begin{tabular}{lcccc}
\hline S1. No. & Substrate & Product & Conversion $^{\mathrm{b}}(\%)$ & Selectivity $(\%)$ \\
\hline 1 & Norbornene & Norbornane epoxide & 99 & 99 \\
2 & Cyclooctene & Octane epoxide & 99 & 99 \\
3 & Cyclohexene & Cyclohexen-1-one & 99 & 72 \\
4 & Styrene & Styrene epoxide & $99^{[\mathrm{d}]}$ & 67 \\
5 & Cyclohexane & Cyclohexane-1-one & $32^{[\mathrm{e}]}$ & 55 \\
6 & Cyclooctane & Cyclooctane-1-one & $65^{[\mathrm{f}]}$ & 52 \\
7 & $1-H e x e n e$ & Hexene epoxide & $99^{[\mathrm{g}]}$ & 39
\end{tabular}

[a] Alkenes/alkanes (400 mmol), TBHP (10 mmol), catalyst $(3.70 \mu \mathrm{mol})$, dichloromethane $(2.0 \mathrm{~mL})$ and dodecane $(5 \mathrm{~mL})$ sealed as internal standard in a Teflon-lined screw capped vial and stirred at room temperature for $6 \mathrm{~h}$. [b] Conversion [\%] and [c] selectivity [\%] were determined by GC. [d] The by-products were benzaldehyde and benzenacetaldehyde. [e] Cyclohexane-1-one (18\%) and cyclohexane-1-ol (14\%). [f] Cyclooctane-1-one (34\%) and cyclooctane-1-ol (31\%). [g] Hexane epoxide (39\%), 1-hexene-3-one (29\%), 2-hexenal (20\%) and by-products were 1-hexene-3-ol (8\%) and 2-hexene-1-ol $(3 \%)$. The yields are w.r.t. oxidant. 
clearly indicates that the new catalyst is a reasonably efficient one.

The oxidizing ability of this new catalyst for other substrates are shown in table 2 . We see that catalysis with catalyst $\mathbf{2}$ are similar with the same substrates (table 3).

Now, we have also investigated the recyclability of the catalyst. Thus, after the completion of the first cycle, the new batch (aliquot) of oxidant was added to the same pot and the product yield was measured. This process was continued for 10 sets. In all cases, we observed that the results of the first cycle was reproduced, confirming that there was almost no catalyst damage in these 10 cycles. We have not measured any further cycles, believing that the catalyst is still surviving as it was in the first cycle. As indicated in table S4, the catalyst 1 was not destroyed in ten cycles, we have measured. The monomeric catalyst, on the other hand, was degraded substantially after the first cycle by the formation of known catalytically inactive $\mu$-oxo-metalloporphyrin dimmers. ${ }^{39}$ The catalyst 1 can be easily separated from the reaction mixture via centrifugation and can be re-used repeatedly.

The comparison of the results of the activity of the monomeric iron and manganese porphyrins versus their perylene linked new catalysts are interesting. The catalyst 1 showed the catalytic activity with $>99 \%$ conversion of norbornene to exo-norbornane epoxide, while the monomeric iron(III) porphyrin has lower catalytic activity with conversion up to only $31 \%$ (table 1). Similarly, monomeric manganese(III) porphyrin has lower catalytic activity with $35 \%$ conversion while catalyst $\mathbf{2}$ gave $99 \%$ conversion (table 1). We believe that the oxidation is proceeding through any of the probable reactive intermediates shown eq. 1 and $2 .^{9}$ The network structure of $\mathbf{1}$ and $\mathbf{2}$ prevents them to form $\mu$-oxo-dimer (eq. 3). This indeed is the reason for the stability and greater efficiency of catalysts $\mathbf{1}$ and $\mathbf{2}$.

$\mathrm{PFe}(\mathrm{III}) \mathrm{Cl}+$ Oxidant $\longrightarrow[\mathrm{PFe}(\mathrm{III})$.oxidant $] \longrightarrow[\mathrm{PFe}(\mathrm{IV}=\mathrm{O})]^{\cdot+}$
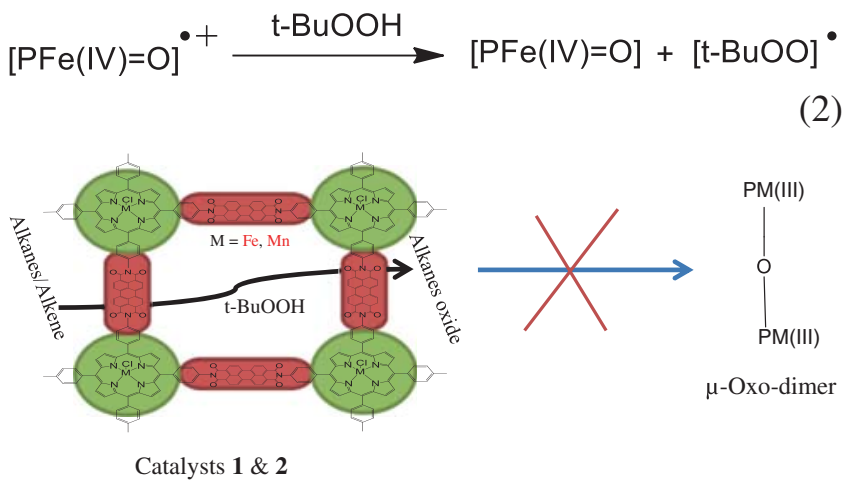

It has been noted that catalyst 2 completes the conversion in $6 \mathrm{~h}$ whereas the corresponding catalyst 1 needs $8 \mathrm{~h}$. The greater surface area of the manganese catalyst $\left(974 \mathrm{~m}^{2} / \mathrm{g}\right)$ compared to iron catalyst $\left(653 \mathrm{~m}^{2} / \mathrm{g}\right)$ could be the reason for this.

\section{Conclusions}

In summary, we have developed the synthesis of two nanoporous perylene based crystalline materials with improved catalytic activity with respect to CMPs, which supports the current thoughts on new COFs. The catalyst materials have very selective oxidizing power for alkanes/alkenes and very good recyclability. Perylene moiety is a very good electron acceptor, so such materials may have good application in optoelectronic devices. With this advancement, we believe that this work will initiate the exploration of various catalytic systems based on COFs via the structural engineering for further improvement of both pores and skeletons.

\section{Supplementary Information}

Synthetic methods and characterization of monomeric free base porphyrins and metalloporphyrins, measurements of FT-IR, EDX, magnetic susceptibility PXRD, pore size and distribution by NL-DFT, Recyclability table for the polymeric materials are available at www. ias.ac.in/chemsci.

\section{Acknowledgements}

We thank the Department of Science and Technology (DST, India) (Project no. SR/S1/IC-48/2010) for funding and UGC for the fellowship to MKS. We also thank Prof. R. Chatterjee of the Dept. of Physics, IIT Delhi for SQUID measurements.

\section{References}

1. Dolphin D and Traylor T G 1997 Acc. Chem. Res. 30 251

2. Suslick K S, Bhyrappa P, Chou J H, Kosal M E, Nakagaki S, Smithenry D W and Wilson S R 2005 Acc. Chem. Res. 38283

3. Che C M and Huang J S 2009 Chem. Commun. 3996

4. Liu W and Groves J T 2010 J. Am. Chem. Soc. 132 12847

5. Zhao M, Ou S and Wu C D 2014 Acc. Chem. Res. 47 1199

6. Chin D H, Mar G N L and Balch A L $1980 \mathrm{~J}$. Am. Chem. Soc. 1024344

7. Traylor T G and Tsuchiya S 1987 Inorg. Chem. 261339

8. Kamaraj K and Bandyopadhyay D 1997 J. Am. Chem. Soc. 1198099 
9. Wadhwani P, Mukherjee M and Bandyopadhyay D 2001 J. Am. Chem. Soc. 12312430

10. Agarwala A and Bandyopadhyay D 2006 Chem. Commun. 4823

11. Moreira M S M, Martins P R and Curi R B 2005 Nascimento O R and Iamamoto Y J. Mol. Catal. A: Chem. 23373

12. Costa A A, Ghesti G F, Macedo J L D, Braga V S, Santos M M, Dias J A and Dias S C L 2008 J. Mol. Catal. A: Chem. 282149

13. Fateeva A, Vinot S D, Heymans N, Devic T, Greneche J M, Wuttke S, Miller S, Lago A, Serre C, Weireld G D, Maurin G, Vimont A and Ferey G 2011 Chem. Mater. 234641

14. Xie M H, Yang X L, Zou C and Wu C D 2011 Inorg. Chem. $\mathbf{5 0} 5318$

15. Chen L, Yang Y, Guo Z and Jiang D 2011 Adv. Mater. 233149

16. Shultz A M, Farha O K, Hupp J T and Nguyen S B T 2011 Chem. Sci. 2686

17. Feng X, Ding X and Jiang D 2012 Chem. Soc. Rev. 41 6010

18. Chen L, Yang Y and Jiang D $2010 \mathrm{~J}$. Am. Chem. Soc. 1329138

19. Kandambeth S, Mallick A, Lukose B, Mane M V, Heine T and Banerjee R 2012 J. Am. Chem. Soc. 134 19524

20. Cote A P, Benin A I, Ockwig N W, O'Keeffe M, Matzger A J and Yaghi O M 2005 Science 3101166

21. Feng X, Chen L, Dong Y and Jiang D 2011 Chem. Commun. 471779

22. Xu H, Chen X, Gao J, Lin J, Addicoat M, Irle S and Jiang D 2014 Chem. Commun. 501292
23. Zhang $\mathrm{W}$, Jiang $\mathrm{P}$, Wang $\mathrm{Y}$, Zhang $\mathrm{J}$ and Zhang $\mathrm{P} 2015$ Catal. Sci. Technol. 5101

24. Ma H, Ren H, Meng S, Sun F and Zhu G 2013 Sci. Rep. 31

25. Meng S, Ma H, Jiang L, Ren H and Zhu G 2014 J. Mater. Chem. A 214536

26. Canivet J, Fateeva A, Guo Y, Coasnecd B and Farrusseng D 2014 Chem. Soc. Rev. 435594

27. Zhang Z, Yao Z, Xiang S and Chen B 2014 Energy Environ. Sci. 72868

28. Modak A, Pramanik M, Inagakibc S and Bhaumik A 2014 J. Mater. Chem. A 211642

29. Kreno L E, Hupp J T and Duyne R P V 2010 Anal. Chem. 828042

30. Wang C, Liu D and Lin W 2013 J. Am. Chem. Soc. 135 13222

31. Liu J, Chen L, Cui H, Zhang J, Zhang L and Su C 2014 Chem. Soc. Rev. 436011

32. Yang X, Xie M, Zou C, He Y, Chen B, O'Keeffe M and Wu C 2012 J. Am. Chem. Soc. 13410638

33. Xu H, Chen X, Gao J, Lin J, Addicoat M, Irle S and Jiang D 2014 Chem. Commun. 501292

34. Chen Y, Hoang T and Ma S 2012 Inorg. Chem. 5112600

35. Nakagaki S, Ferreira G K B, Ucoski G M and Castro K A D F 2013 Molecules 187279

36. Larsen L W, Wojtas L, Perman J, Musselman R L, Zaworotko M J and Vetromile C M $2011 \mathrm{~J}$. Am. Chem. Soc. 13310356

37. Ding S and Wang W 2013 Chem. Soc. Rev. 42548

38. Singh M K and Bandyopadhyay D 2014 J. Chem. Sci. 1261707

39. Li C, Qui W, Long W, Deng F, Bai G, Zhang G, Zi X and He H 2014 J. Mol. Catal. A: Chem. 393166 